\title{
Non-destructive testing of bored piles
}

\author{
DAssel Tulebekova, ${ }^{1, *}$, (D) Nurgul Shakirova ${ }^{2}$, (D) Aizhan Zhankina ${ }^{1}$, (D Yerbolat Muratov ${ }^{1}$ \\ ${ }^{1}$ Department of Civil Engineering, L.N. Gumilyov Eurasian National University, Nur-Sultan, Kazakhstan \\ ${ }^{2}$ KGS, LTD, Nur-Sultan, Kazakhstan \\ *Correspondence: krasavka5@mail.ru
}

\begin{abstract}
Quality control of bored piles is a complex operation aimed at determining possible defects in the pile shaft and the strength of the pile material made by different technologies. The presence of pile shaft defects and a decrease in the strength characteristics of the pile shaft material lead to the development of negative processes at the stage of subsequent operation of the building and structure. It is known that the bearing capacity of the pile material should not be less than the bearing capacity of the ground. Consequently, it is necessary to strictly observe the quality of the concrete of the design strength values to ensure the reliability of the designed building concerning the service life. Nowadays different methods of nondestructive testing such as pile integrity test, cross-hole sonic logging. The paper presents a discussion of the advantages and disadvantages of each of them, experimental data also are given.
\end{abstract}

Keywords: pile, test, soil, integrity, method

\section{Introduction}

\section{General provisions}

Due to the multistage and complexity of the bored pile manufacturing process, as well as the dependence of the result on the human factor, various defects can appear in the piles: zones of complete absence of concrete, porosity, decreased concrete strength, inclusions of natural soil. Deviation in manufacturing from the design characteristics of the pile in length, continuity, shape, diameter, the strength of the concrete, size of the armature leads to a loss of bearing capacity of the pile and settlement of bridges and foundations, up to the destruction of buildings and structures. The term "continuity of concrete" is understood as "an indicator of the quality of paving, characterizing the continuity of the material and the absence of abnormal zones (sludge, voids)" [1-3]. Traditional tests of piles with static and dynamic loads, being the most representative tests, can only determine the carrying capacity of piles, but in no way can guarantee the quality of the pile as a reinforced concrete structure, that is why the international standards provide for the bored pile bore integrity control. Because direct methods of control, including testing of piles by traditional methods, sampling with subsequent testing in the laboratory, and some others, are time-consuming and costly. Therefore, there is a need for investigation for inexpensive and non-destructive control methods that allow for quick observations.

\subsection{Testing methods for pile foundations in different stages of investigations}

Engineering geological investigations considered three stages which are shown in Table 1. Testing methods for pile foundations in different stages of investigations include the follows weight sounding test (WST); cone penetration test (CPT); dynamic probing tests (DP); standard penetration test (SPT); field vane test (FVT); pressuremeter test (PMT); static axially loaded compression; pile integrity tests and determination of a pile length. In pile integrity tests, the highest quality signals are achieved by observing the following: 
- blow zones of concrete foundation construction should be trimmed back to sound material, free of loose surfaces and debris;

- the surface should be free of water;

- any structures or elements attached to the concrete foundation construction, e.g., long projecting reinforcement or cages, may return signals generated by these elements which may make the signal impossible to interpret. Often, interference from these elements may be electronically filtered out;

- access to the side of the pile should permit delivery of several hammer blows and provide sufficient room for movement of the transducers on the side; for testing;

- concrete foundation construction normally requires a curing time of 28 days to being ready

- several blows should be delivered to each test place to ensure repeatability and hence consistency of results.

Table 1 - Testing methods for pile foundations in different stages of investigations

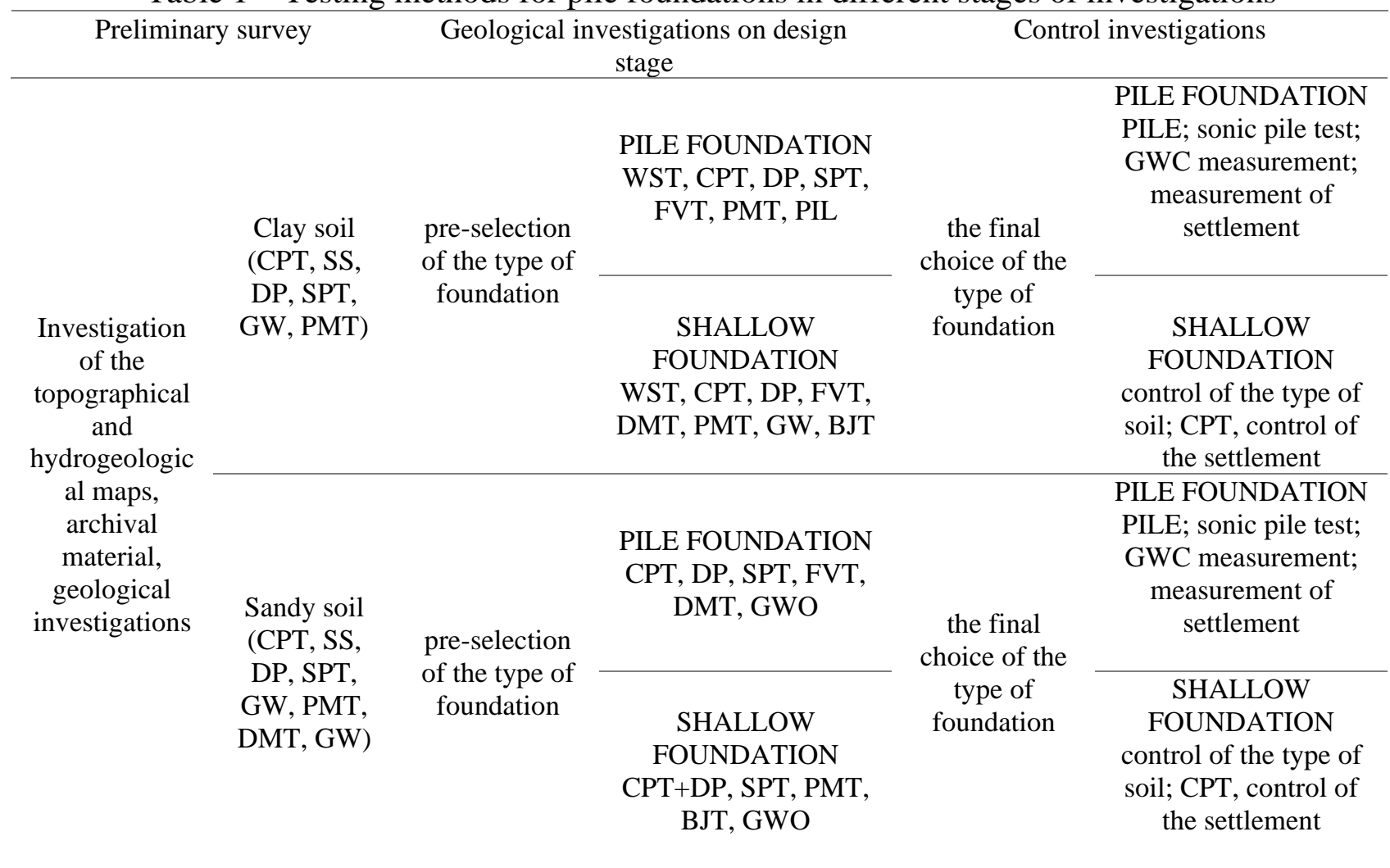

The test procedure associated with a pile integrity test consists of the following steps [5]:

- clearing of the concrete pile from the soil, snow, ice to the sound surface. Preparation of three zones (if possible) of flat, dry concrete on the pile; the size of such zones should be approximately $100 \times 100 \mathrm{~mm}$ to attach the sensor (accelerometer) and to blow by a special hammer on the concrete surface;

- the following parameters are introduced in memory of the device: Site, symbol of concrete foundation, length, stress wave velocity in concrete;

- the sensor, registering reflected signals is fixed on a prepared zone on the pile through special paste for best registration of the signals. Three light blows are produced by a special hammer on the foundation site of the prepared place. The graph (reflectogram) of blow amplitude to the length of concrete foundation dependence is represented on the display of the device. If the operator determines graphs to be acceptable for interpretation, these results are written into the memory of the device for additional processing. If the blows were either very strong or very weak, the device does not register 
any signal and it is required to repeat the blow. The blows are produced until the operator can interpret the reiterative graphs (reflectograms).

All integrity tests data are processed by special software after testing, and output is represented by a graph "signal amplitude" - "crack location". According to the graphs the operators classify the depth of crack penetration. A technical report will be given to the client after all tests with detailed analysis.

The pile side is struck with a hand-held hammer that sends sound waves directly through the concrete foundation. Pile side movements affected by a series of hammer blows and subsequent rebounds are then received by a very sensitive acceleration meter positioned on the side of the foundation. The acceleration signal is converted into velocity and is represented on the screen as a function of time. All results are easily saved into the computer, to be used in the processing thereof.

The interpretation of reflectograms consists of the following actions [4-5]:

- If the graph has clear fluctuations with a further reflection of the signal, it means the pile has experienced necking, cracking, incursions, geological influence, etc.;

- If such fluctuations are not significant, it means that the pile is without defects.

- has necking, the influence of geological conditions (e.g., soils filled by water), change of density of soil or concrete, etc.

- If the graph has sharp fluctuations, it means that the pile has serious cracking/necking in the place of the beginning of fluctuation.

\section{Methods}

\subsection{Pile Integrity Testing in Object 1}

Work on continuity diagnostics and length control of 18 bored piles at the Bridge site [6] (Figure 1). The bored piles were erected using rotary drilling technology with inventory casing. Equipment used during the test: pile diagnostic unit Spektr, seismic receiver, hammer with nozzles of different stiffness, software Spektr [7].
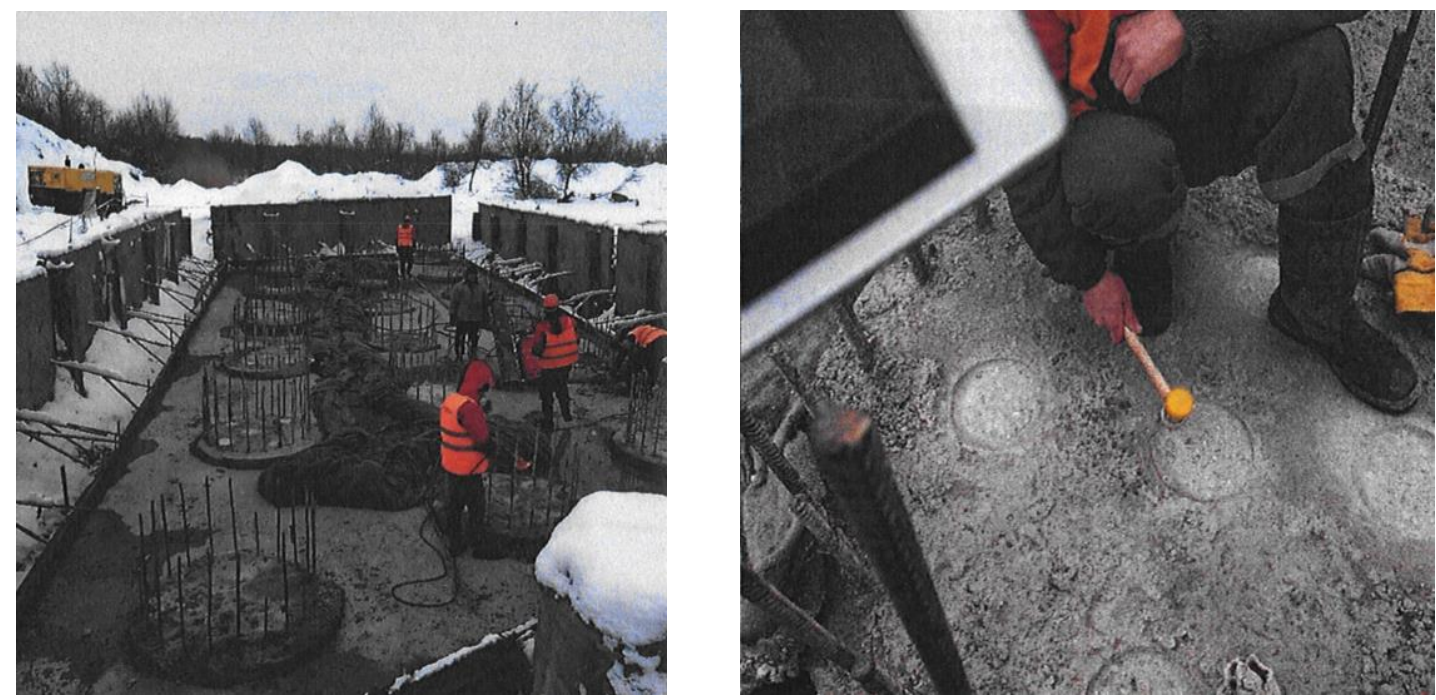

Figure 1 - Constriction site of 18 bored piles

The number of sensors to be installed and their location and impact locations are set for each pile separately. To increase reliability, the sensors are installed on several control points (at least 3 per pile). To press and fix sensors on the pile a special viscous composition is used, which provides tight contact of sensors with the pile. To excite the pulses passing through the pile for each method of control, at least 10 impacts were made. The measurement technique was carried out according to ASTM requirements. The sensor-accelerometer depending on the design features of the object of the conditions of access to the pile was installed in accordance with the diagrams shown in figure 2. 


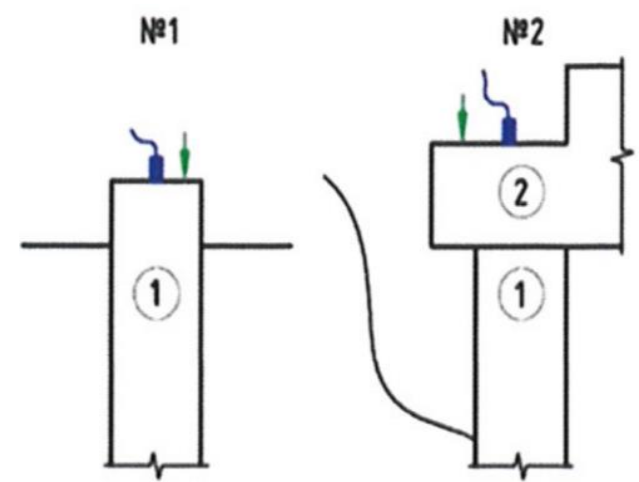

№1 - on the pile head
№2 - overhead

Figure $2-\mathrm{P}$

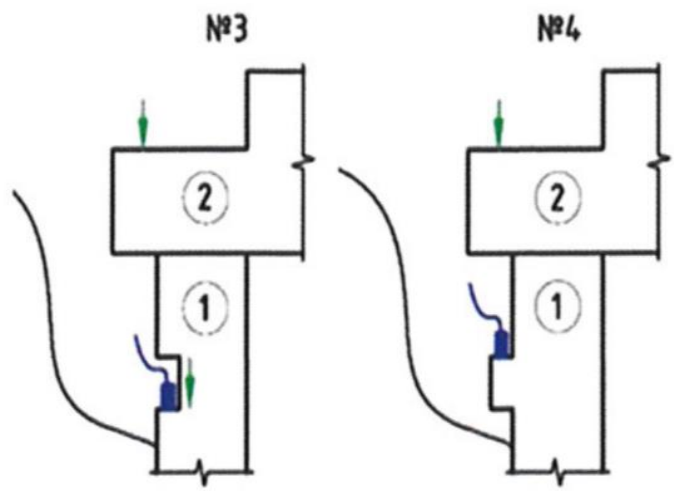

№ 3,4 - to the site prepared above the pile
No5

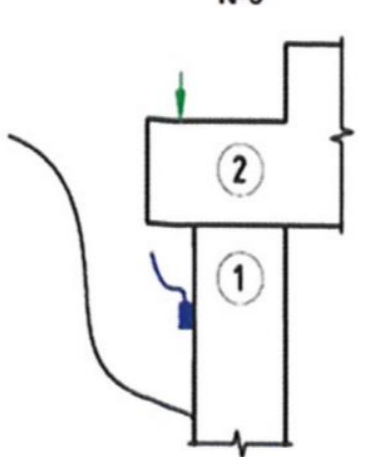

№5 - on the side surface of the pile

In the course of the study, preference was given to Scheme №1. The first stage included applying a series of blows, the second stage involved determining the speed of propagation of the acoustic wave rod in the pile concrete. The average velocity is taken in the range of $3600-4100 \mathrm{~m} / \mathrm{s}$, and the third stage - the cameral processing. The results of testing 9 piles are shown in Table 2 and Figures 3-6.

Table 2 - Results of measured pile length

\begin{tabular}{ccc}
\hline Number of pile & Measured pile length, m & Result of testing \\
\hline 1 & 25.3 & satisfactory \\
\hline 2 & 25.7 & satisfactory \\
\hline 3 & 26.8 & satisfactory \\
\hline 4 & 26.2 & satisfactory \\
\hline 5 & 26.4 & satisfactory \\
\hline 6 & 25.6 & satisfactory \\
\hline 7 & 25.9 & satisfactory \\
\hline 8 & 26.3 & satisfactory \\
\hline 9 & 25.5 & satisfactory \\
\hline
\end{tabular}

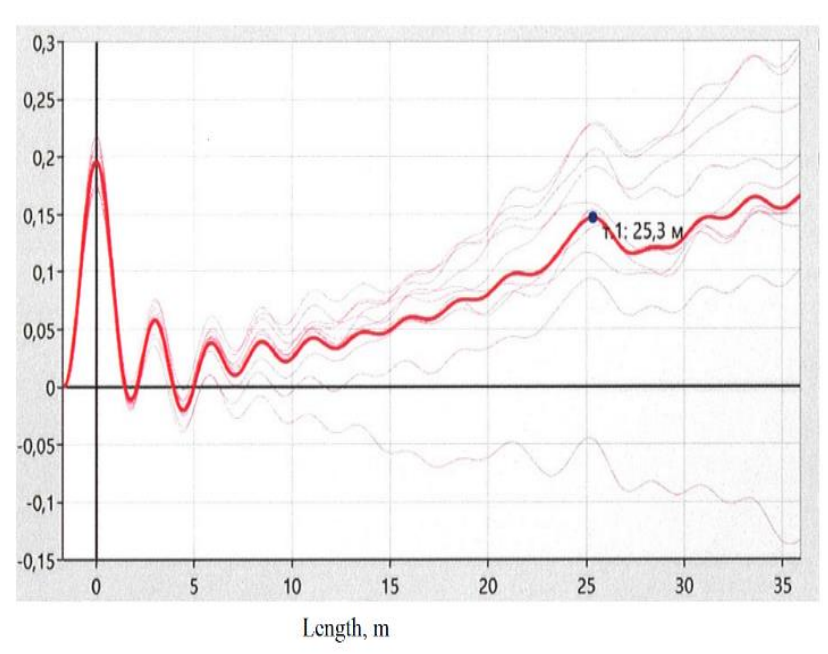

Figure 3 - Analysis of the wave passage through the body of the pile 1

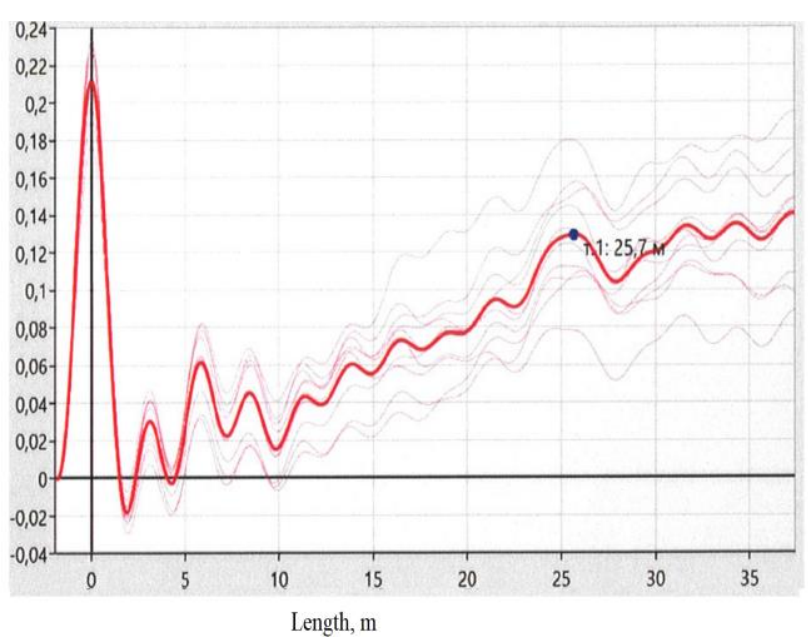

Figure 4 - Analysis of the wave passage through the body of the pile 2 


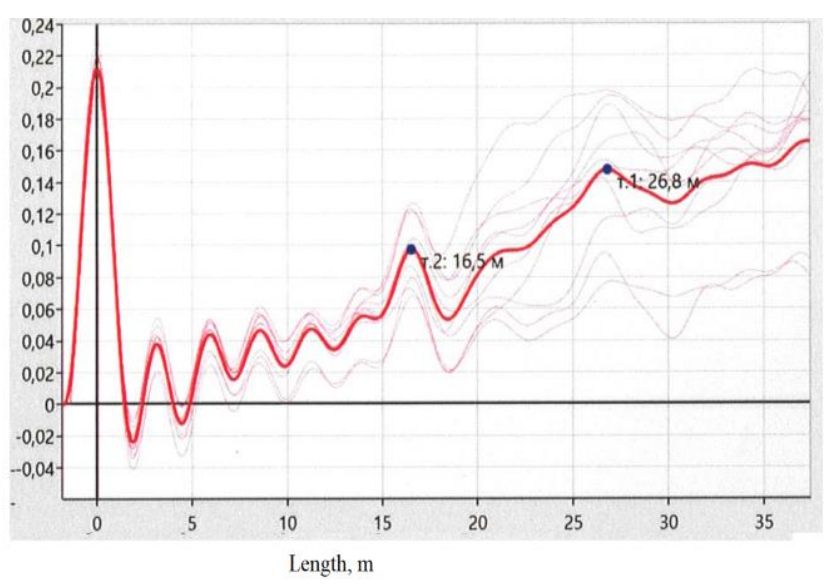

Figure 5 - Analysis of the wave passage through the body of the pile 3

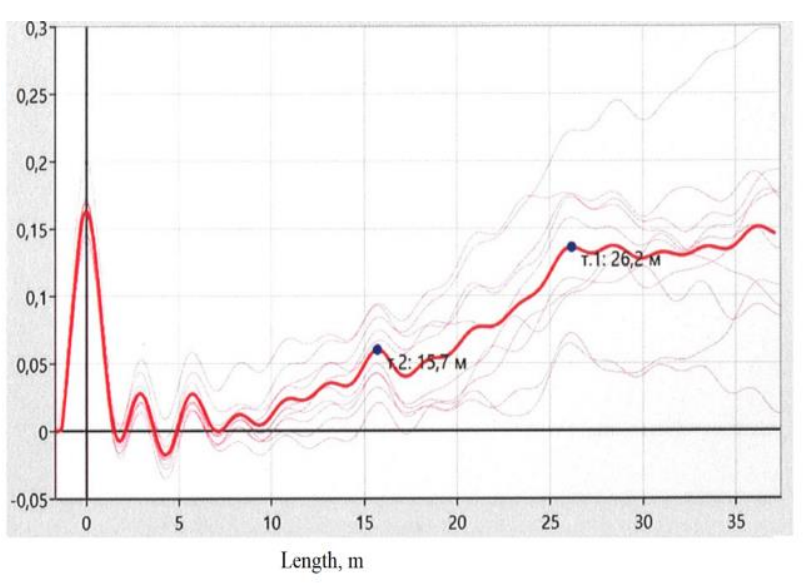

Figure 6 - Analysis of the wave passage through the body of the pile 4

\subsection{Cross hole sonic logging test}

Also in practice, the cross-hole sonic logging (CSL) method is used. Inspection of piles by the CSL method [8] is based on determining the properties of the inspected object by changing one of the parameters of the ultrasonic wave passed through the inspected area of the pile [7-8]. The ultrasonic wave is transmitted from the transmitter to the receiver in the form of pulses with a set. The transducers are pulled through water-filled tubes installed in the frame of the pile under study. The amplitude of the ultrasonic wave passing through the monitored area and the time of its passage are used as the registered parameter [9-10].The measured transit time and energy of ultrasonic waves correlate unambiguously with the quality of concrete. The signals coming from the measuring instruments during the ultrasonic wave transit are recorded and processed on the PC, and then provided as the sought information about the integrity and homogeneity of the pile shaft. The CSL were conducted at the construction site of Nur-Sultan (Figure 7). The data of testing bored pile is presented in Table 3 and results in Table 4 and Figure 8-9 [11].
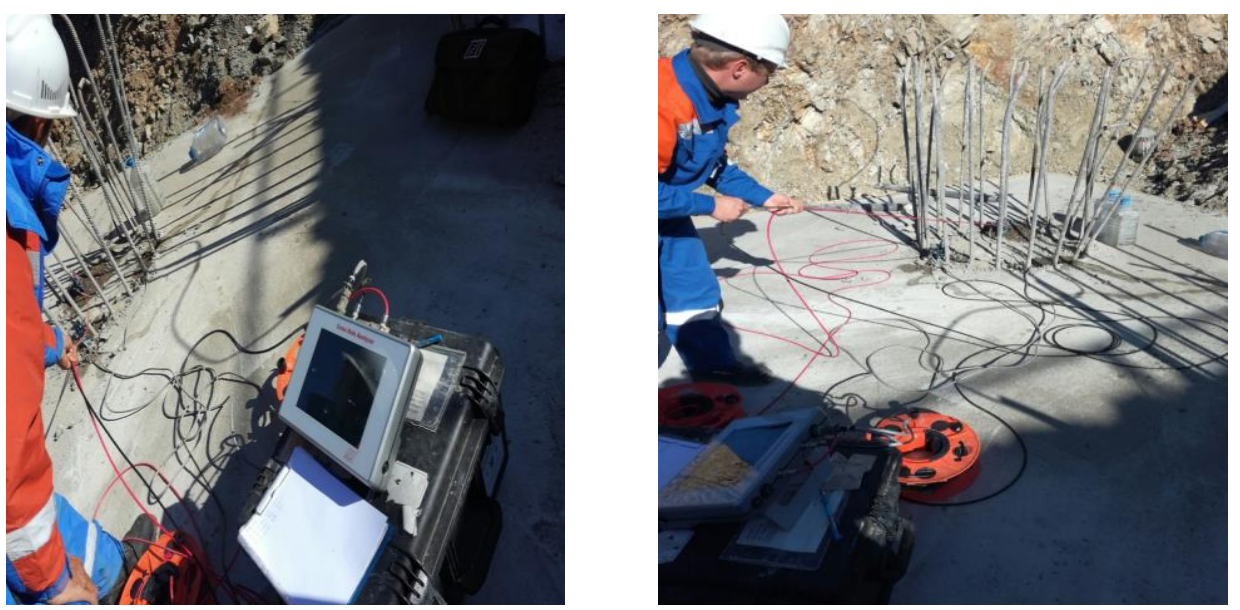

Figure 7 - Testing in construction site

Table 3 - Data of testing pile

\begin{tabular}{lcccc}
\hline \multicolumn{1}{c}{$\begin{array}{c}\text { Number of } \\
\text { piles }\end{array}$} & Pile length, $\mathrm{m}$ & $\begin{array}{c}\text { Diameter } \\
\text { of the pile, } \\
\mathrm{m}\end{array}$ & $\begin{array}{c}\text { Number of test } \\
\text { tubes / their } \\
\text { diameter, } \mathrm{m}\end{array}$ & $\begin{array}{c}\text { Height of test } \\
\text { tubes above the } \\
\text { pile concrete, } \mathrm{cm}\end{array}$ \\
\hline $\begin{array}{l}\text { Entry and exit } \\
\text { line, YCR13 } \\
\text { support, pile 1 }\end{array}$ & 53.1 & 1.5 & $3 / 42$ & 5 \\
\hline
\end{tabular}


Table 4 - Results of a testing pile

\begin{tabular}{|c|c|c|c|c|}
\hline $\begin{array}{c}\text { Number of } \\
\text { piles }\end{array}$ & $\begin{array}{c}\text { Test tube pair } \\
\text { numbers }\end{array}$ & $\begin{array}{c}\text { Distance } \\
\text { between the } \\
\text { test tubes, m }\end{array}$ & $\begin{array}{l}\text { Available length } \\
\text { of test tubes, m }\end{array}$ & Results of test \\
\hline \multirow{3}{*}{$\begin{array}{l}\text { Entry and exit } \\
\text { line, YCR } 13 \\
\text { support, pile } 1\end{array}$} & $1-2$ & 1.000 & $53.10 / 53.10$ & \multirow{3}{*}{$\begin{array}{c}\text { The defect } \\
\text { was detected } \\
\text { at a depth of } \\
22.64-24.59 \mathrm{~m}\end{array}$} \\
\hline & $1-3$ & 0.930 & $53.10 / 53.10$ & \\
\hline & $2-3$ & 1.010 & $53.10 / 53.10$ & \\
\hline
\end{tabular}

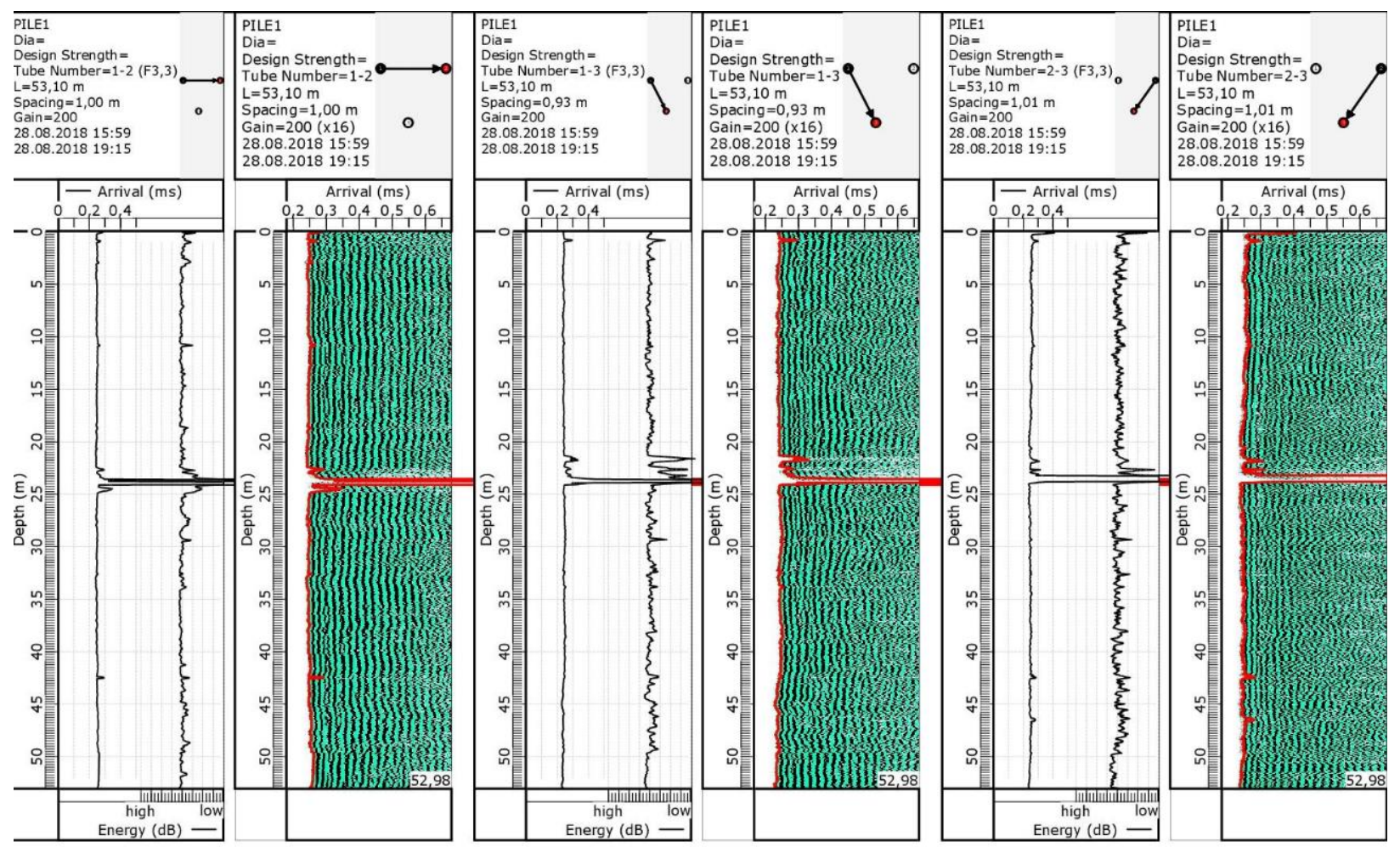

Figure 8 - Results of measurement
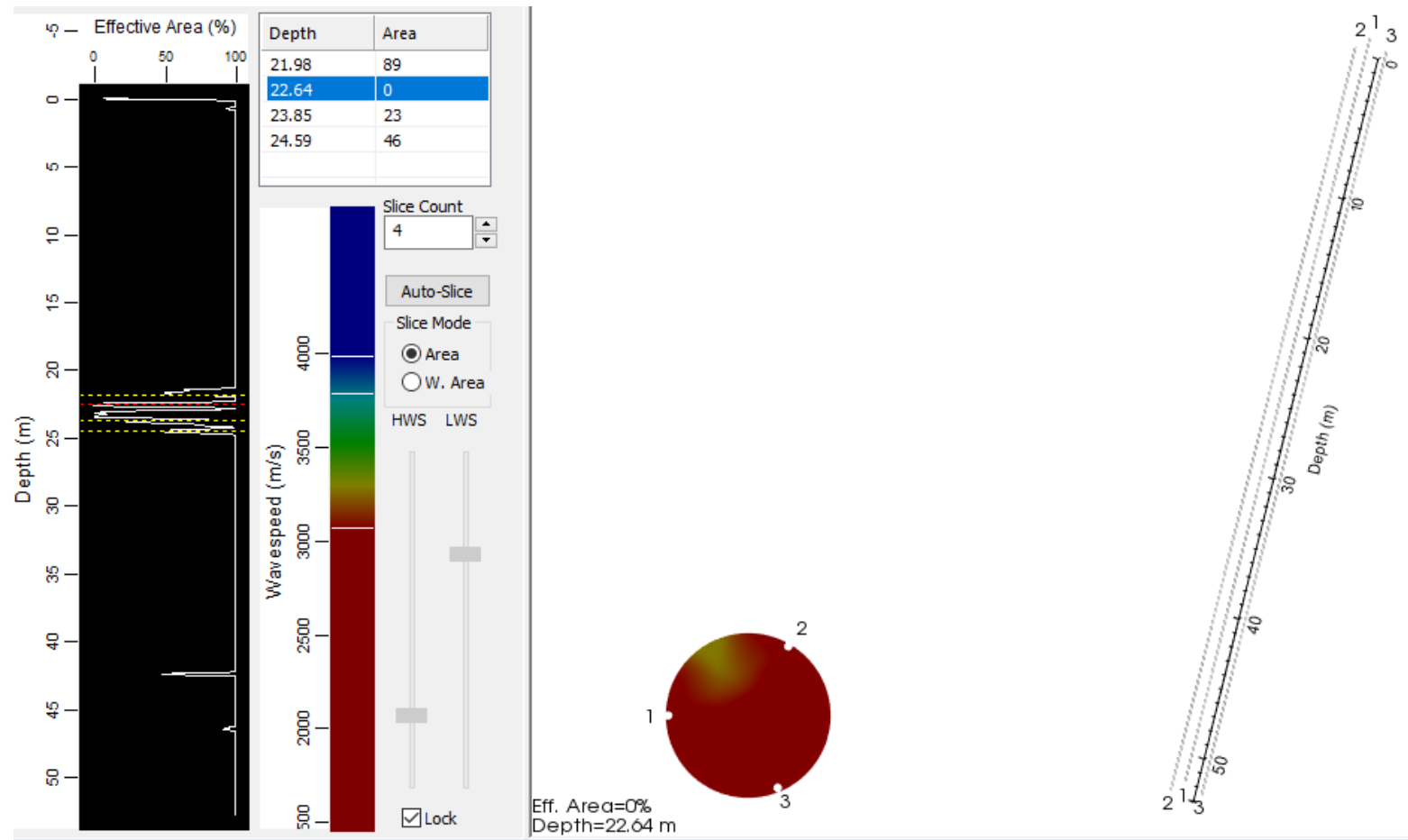

Figure 9 - PDI-TOMO measurement results 


\section{Results and Discussion}

The PIT method and the CSL method provide data on the quality of piles with a significant degree of reliability in a relatively short time. However, in the course of the study, it is possible to highlight such features as presented in Table 5.

Table 5 - Advantages of PIT and CSL

\begin{tabular}{lcc}
\hline \multicolumn{1}{c}{ Indicators } & PIT & CSL \\
\hline Number of tests per day & $\checkmark$ & \\
\hline Measures to prepare for the test & $\checkmark$ & $\checkmark$ \\
\hline Pile length variations & & $\checkmark$ \\
\hline Detection of defects of different nature & $\checkmark$ & \\
\hline Interpretation of results & & \\
\hline
\end{tabular}

Thus, the advantages of the PIT are a very quick data acquisition on any pile on the construction site and the ability to check up to 100 piles per day; pile length within $100 \mathrm{~m}$; identification of defects of different nature in the barrel of the reinforced concrete pile; the possibility of diagnosing any pile by one operator independently; maintaining the integrity of the pile; relatively low cost of the test.

Advantages of CSL is no pile length limitation; can determine the depth of an anomaly with reasonable accuracy; can estimate horizontal extent of a defect if enough access tubes are present.

\section{Conclusions}

The PIT method allows an expert assessment of the actual condition of the pile, determines its length, and analyzes the integrity of the structure. This method is an expression control and does not destroy the concrete of the pile. The PIT method makes it possible to obtain, with a high degree of certainty and in a relatively short time, data on the load-bearing capacity of the pile. The CSL method of concrete structure continuity control is based on the difference of velocities of ultrasonic waves in environments with different structures, mechanical and physical properties.

However, as the study showed, there are disadvantages of each of them, among which we can highlight: access tubes must be cast during shaft construction; evaluation often requires experience and engineering judgment when results are complicated or not outwardly conclusive; inconclusive results or complicated signals can be caused by several factors. In this regard, it is necessary to use a comprehensive approach using these two methods.

\section{Acknowledgments}

The authors would like to gratitude «KGS-Astana», LTD, «Alsim Alarko" JSC.

\section{References}

1. Defect Analysis for CSL Testing / G. Likins, F. Rausche, K. Webster, A. Klesney // Contemporary Issues In Deep Foundations. - Reston, VA: American Society of Civil Engineers, 2007. — C. 1-10. DOI: 10.1061/40902(221)3.

2. Nondestructive Evaluation of Drilled Shaft Construction Anomalies Using Full Waveform Tomography of Simulated Crosshole Measurements / A. Kordjazi, J.T. Coe, M. Afanasiev // Journal of Nondestructive Evaluation. — 2021. — Vol. 40, № 1. - C. 3. DOI: 10.1007/s10921-020-00728-8.

3. Evaluation of Thermal Integrity Profiling and Crosshole Sonic Logging for Drilled Shafts with Concrete Defects/ A.Z. Boeckmann, J.E. Loehr // Transportation Research Record: Journal of the Transportation Research Board. — 2019. — Vol. 2673, № 8. - C. 86-98. DOI: 10.1177/0361198119842112.

4. Comparing cross-hole sonic logging and low-strain integrity testing results / R. White, B., Nagy, M. \& Allin // The 8th International Conference on the Application of Stress wave theory to piles 2008. - C. 471-476.

5. Low Strain Detection and Numerical Simulation of Pile Integrity / L. Wei // IOP Conference Series: Earth and Environmental Science. — 2021. — Vol. 825, № 1. — C. 012026. DOI: 10.1088/1755-1315/825/1/012026.

6. Testing of piles for continuity / LTD. Test Construction -2020. 
7. Standard Test Method for Integrity Testing of Concrete Deep Foundations by Ultrasonic / ASTM Standard D 6760 $-2002$.

8. Standard Test Method for Low Strain Impact Integrity Testing of Deep Foundations / ASTM Standard D 5882 2000.

9. Crosshole Sonic Logging of South Carolina Drilled Shafts: A Five Year Summary / W.M. Camp, III, D.W. Holley, G.J. Canivan // Contemporary Issues In Deep Foundations. - Reston, VA: American Society of Civil Engineers, 2007. - C. 1-11. DOI: 10.1061/40902(221)2.

10. Closure to "Load Transfer Curve Analyses of Drilled Shafts Using Crosshole Sonic Logging Test" by Won-Taek Hong, Seung Yong Shin, Min-Chul Park, Jong-Sub Lee, and Myung Jun Song / W.-T. Hong, S.Y. Shin, M.-C. Park, J.-S. Lee, M.J. Song // Journal of Geotechnical and Geoenvironmental Engineering. — 2020. — Vol. 146, № 7. — C. 07020009. DOI: 10.1061/(ASCE)GT.1943-5606.0002285.

11. Conclusion on testing of bored piles by interdigitated defectoscopy / LTD. KGS-Astana - 2018.

\section{Information about authors:}

Assel Tulebekova - Assoc. Prof. PhD, Associate Professor, Department of Structural Engineering, L.N. Gumilyov Eurasian National University, Nur-Sultan, Kazakhstan, krasavka5@ mail.ru

Nurgul Shakirova - PhD, Scientific Researcher, KGS, LTD, Nur-Sultan, Kazakhstan, nur_shakirova77@mail.ru

Aizhan Zhankina - PhD Student, Department of Structural Engineering, L.N. Gumilyov Eurasian National University, Nur-Sultan, Kazakhstan, zhankina_aizhan@mail.ru

Yerbolat Muratov - MSc Student, Department of Structural Engineering, L.N. Gumilyov Eurasian National University, Nur-Sultan, Kazakhstan, yerbolat2805@bk.ru 